ENCYCLOPEDDIE Encyclopédie berbère

BERBERE

15 | 1995

15 | Daphnitae - Djado

\title{
Dar bel Ouar
}

(voir Enfida)

G. Camps

\section{OpenEdition}

Journals

Édition électronique

URL : http://journals.openedition.org/encyclopedieberbere/2214

DOI : 10.4000/encyclopedieberbere.2214

ISSN : 2262-7197

Éditeur

Peeters Publishers

Édition imprimée

Date de publication : 1 avril 1995

Pagination : 2223-2226

ISBN : 2-85744-808-2

ISSN : 1015-7344

Référence électronique

G. Camps, «Dar bel Ouar », Encyclopédie berbère [En ligne], 15 | 1995, document D13, mis en ligne le 01 juin 2011, consulté le 24 septembre 2020. URL : http://journals.openedition.org/encyclopedieberbere/ 2214 ; DOI : https://doi.org/10.4000/encyclopedieberbere.2214

Ce document a été généré automatiquement le 24 septembre 2020.

(c) Tous droits réservés 


\section{Dar bel Ouar}

(voir Enfida)

\section{G. Camps}

1 L'une des plus importantes nécropoles mégalithiques de l'Enfida* (Tunisie orientale). En 1875, Rebatel et Tirant décrivaient cette nécropole et y dénombraient 250 à 300 dolmens «en parfait état de conservation». En 1881, plusieurs de ces monuments furent fouillés par le capitaine Bordier ; l'année suivante l'aide-major Chopinet visite à son tour cette nécropole qu'il décrit sous le nom d'Enfida. Cette dénomination est insuffisante car elle s'applique, en fait, à toute la région bordée par la courbe sud du golfe de Hamamet et dont Dar bel Ouar est approximativement le centre. Il faut dire que l'imprécision toponymique est grande: Dar bel Ouar (orthographié parfois Dar Bellouar) est aussi appelé Bordj Bel Ouar, Menzel Bel Ouar et même Hadjar bel Ouar. C'est ce dernier nom que connaissent Cagnat en 1885 et Hamy en 1904. La description la plus complète est donnée par le Dr Hamy, qui fut le seul auteur à avoir séjourné dans la région, encore n'y resta-t-il qu'une dizaine de jours.

2 Les dolmens de l'Enfida appartiennent au type des dolmens* littoraux du Maghreb, c'est dire qu'ils possèdent une enceinte circulaire faite généralement d'une seule rangée de pierres et un couloir à ciel ouvert. La chambre et parfois le couloir peuvent être dallés. Le Dr Hamy précise que les dolmens encore debout ont un orthostate monolithique sur trois côtés de la chambre ; le quatrième, qui est à l'est, est aujourd'hui béant mais à l'origine, ce côté était constitué d'un muret en pierres sèches. Le couloir aboutit à cette ouverture de la chambre, il est le plus souvent perpendiculaire à ce petit côté, mais il peut être plus ou moins oblique lorsque le monument réunit dans la même enceinte plusieurs chambres qui conservent chacune leur couloir. Le cercle de pierres est plus ou moins régulier suivant la qualité ou la taille des blocs utilisés. 


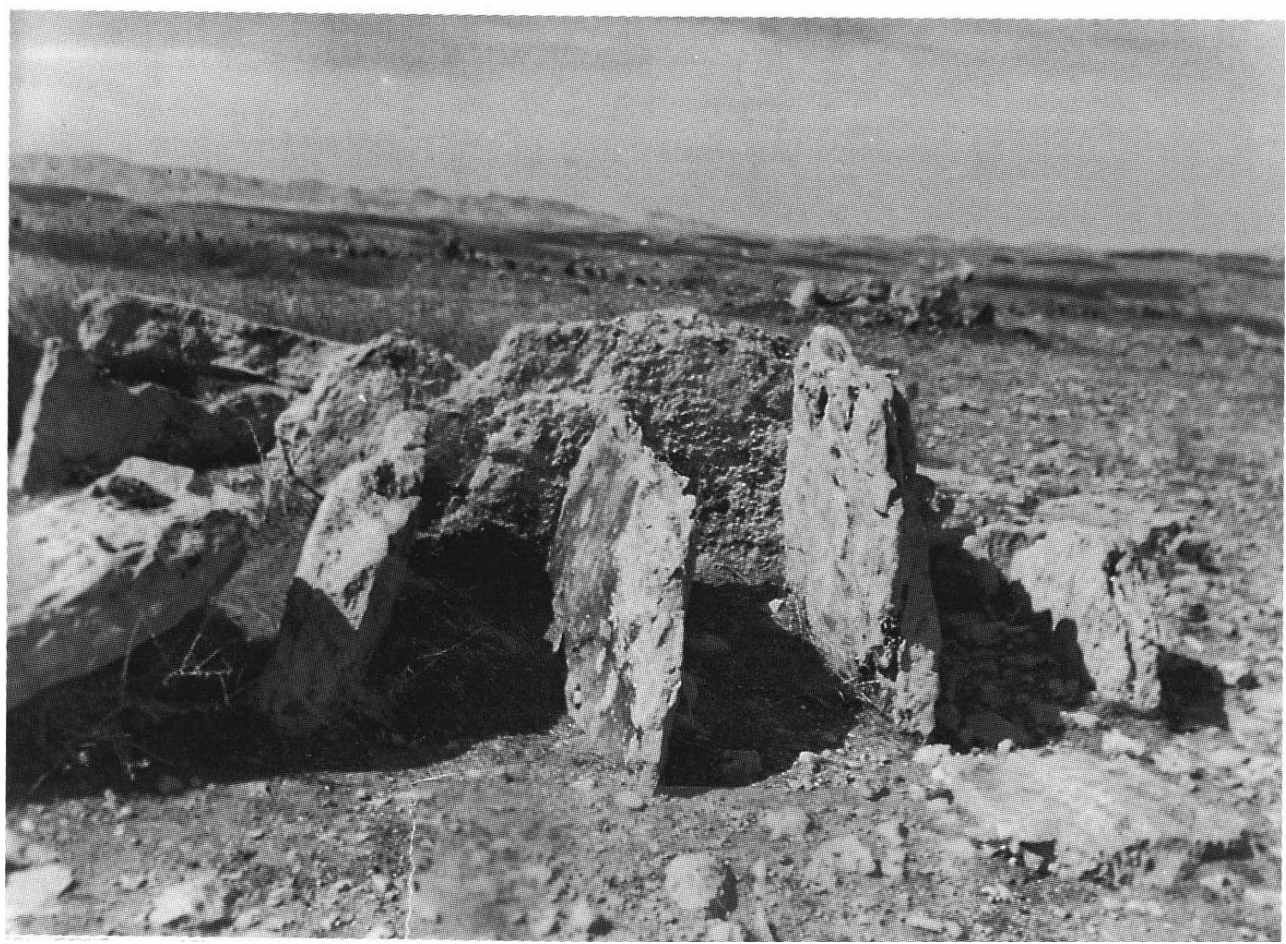

3 Comme dans les autres nécropoles de l'Enfida, d'autres types de tombes peuvent être associés aux dolmens, ce sont principalement des bazinas*, les unes cylindrotronconiques surbaissées, les autres à degrés de très faible hauteur. Elles ont entre 7 et $8 \mathrm{~m}$ de diamètre, ce qui est aussi celui des enceintes des dolmens. Certaines bazinas ont leur chambre complètement enterrée, le couloir est alors en pente, voire remplacé par un véritable escalier.

4 Ces monuments si nombreux n'ont livré aux fouilleurs qu'un mobilier misérable : une demi-douzaine de vases modelés et mal cuits, dont un gobelet à anse, forme plutôt archaïque dans la céramique protohistorique du Maghreb. Les ossements découverts dans ces tombes mégalithiques n'ont pu être conservés mais on a pu reconnaître que les corps avaient été déposés en décubitus latéral fléchi ; constatation qui depuis a été confirmée dans les autres sépultures protohistoriques de l'ensemble du Sahel. Les Libyens restaient encore fidèles à cette position à la fin des temps puniques.

5 L'estimation du nombre des monuments constituant la nécropole de Dar bel Ouar est sujette à des variations considérables. Pour Rebatel et Tirant, il y aurait eu 250 à 300 dolmens dans la nécropole, en 1875 ; Chopinet en compte une centaine encore debout en 1882, mais il estime à 3000 le nombre des dolmens ruinés; deux ans plus tard, Cagnat parlait encore d'un « immense champ de dolmens sur un espace d'un kilomètre carré au moins »; en 1886, Rouire attribuait à la nécropole 800 monuments occupant une aire de 250 ha.

6 Quelque soit le nombre exact de monuments, il est sûr que la nécropole de Dar bel Ouar comptait parmi les plus importantes de l'Afrique du Nord or il n'en reste plus aujourd'hui que quelques dalles éparses et un seul dolmen ruiné à Dar bel Ouar même, village de création récente dont la construction s'est faite aux dépens de la nécropole mégalithique dans l'indifférence générale. Les rédacteurs de la feuille de Sousse de l'Atlas préhistorique de Tunisie n'ont pu, ces dernières années, que constater les dégâts 
irrémédiables. La destruction totale de la nécropole de Dar bel Ouar, ainsi que de la plupart des tombes mégalithiques de l'Enfida, est incontestablement un désastre archéologique.

Dolmen double opposé d'Hendir el-hadjar, d'après Hamy
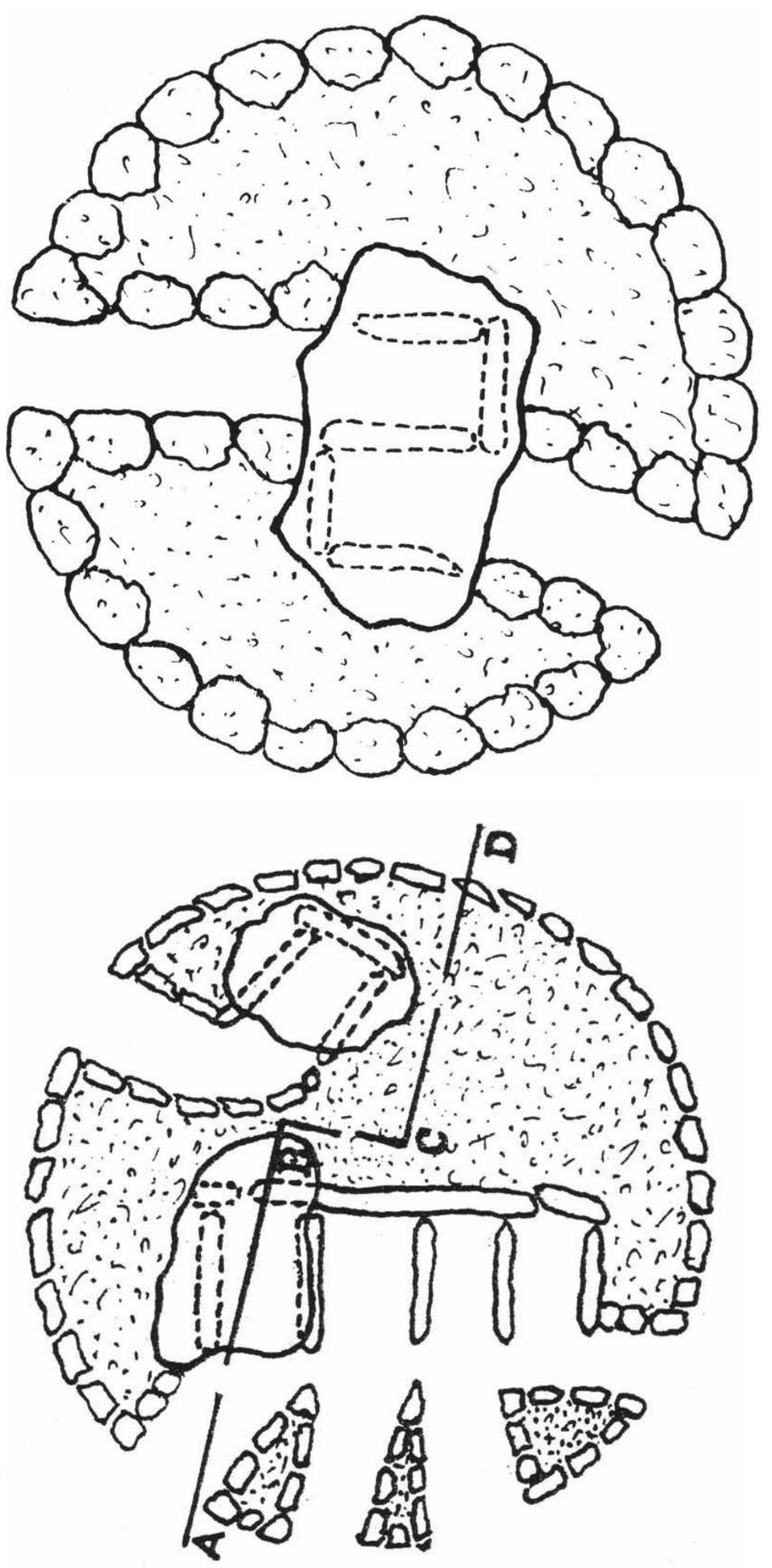


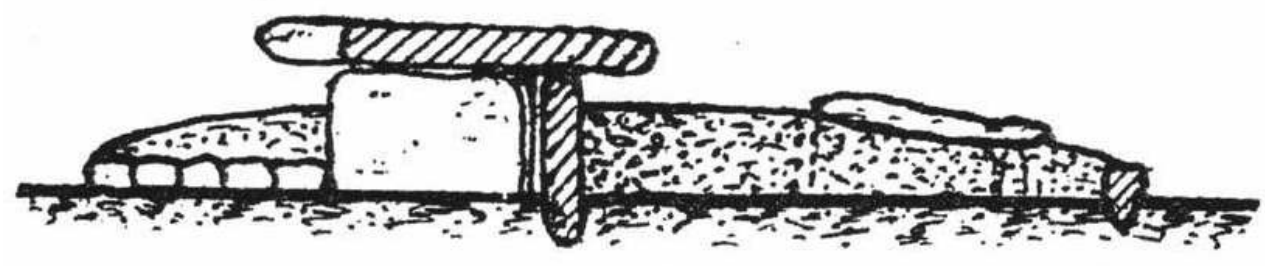

\section{BIBLIOGRAPHIE}

REBATEL et TIRANT, « Voyage dans la régence de Tunisie », Le Tour du Monde, $1^{\mathrm{er}}$ semestre 1875, p. 318.

CHOPINET Dr., « Une colonne dans l'Enfida de Tunisie », Bull, de la Soc. de Géogr. de Toulouse, n 7, 1882, p. 212-213.

CAGNAT R.,«Rapport sur une mission en Tunisie », Archives des Missions, $3^{\mathrm{e}}$ série, t. XI, 1885, p. 35-37. ROUIRE Dr., « Notes sur les dolmens de l'Enfida », Rev. d'Ethnogr. t. V, 1886, p. 441-448.

HAMY M.T., « Cités et nécropoles berbères de l'Enfida », Bull, de Géogr. hist, et descript., nº 1, 1904, p. 33-68.

DEYROLLE Dr., « Note sur les dolmens de Dar Bel Ouar et leur mobilier funéraire », Bull, de la soc. archéol. de Sousse, 1908, p. 60-61.

Atlas préhistorique de la Tunisie. Feuille de Sousse, $n^{\circ} 8$ Dar Bel Ouar. Ecole franc, de Rome et INAA de Tunis. Rome 1992.

\section{INDEX}

Mots-clés : Protohistoire, Tunisie 